\title{
O processo de aquisição das vogais semi-abertas "é, ó" / $\varepsilon, 0 /$ do portugues (brasileiro) como lingua estrangeira
}

\author{
1. Introdução
}

U ma das características mais notáveis dos programas de português como língua estrangeira nas universidades americanas é a heterogeneidade dos grupos de estudantes. Outros programas de línguas estrangeiras às vezes apresentam essa característica. Porém, o que se observa nos outros programas de línguas estrangeiras não afeta o rendimento na sala de aula tanto quanto o que estamos acostumados a presenciar nos programas de português. Vários são os fatores que levam os programas de português a essa situaçào: limitado número de matrículas, falta de exames preliminares à entrada dos estudantes, ${ }^{1}$ falta de interesse pelos programas de português, além de outros fatores que fazem com que a formação de grupos nas salas de aula com experiência similar no aprendizado de línguas estrangeiras seja um privilégio relegado às línguas estrangeiras mais populares. Dentre esses fatores, aquele que parece merecer prioridade é o fator nível de experiência do estudante no que se refere à língua estrangeira.

De uma maneira geral, esses grupos heterogêneos são constituídos de estudantes que tomam uma cadeira em língua estrangeira pela primeira vez, estudantes com um conhecimento muito bom de uma língua estrangeira, especialmente oespanhol, estudantes bilíngües em inglês e espanhol ou outras línguas. $O$ professor face a tal desequilíbrio encontra dificuldades para estabelecer não só um método de ensino como também os critérios a utilizar numa avaliação justa dos estudantes que compöem esses grupos. Se para alguns estudantes nesses grupos heterogêneos a aula parece demasiado lenta, para outros o ritmo de trabalho é o ideal e para terceiros talvez seja muito rápido. Essa questão vem preocupando muitos educadores nos EUAe no Brasil há algum tempo, porém ainda não se conseguiu solucionar este problema apesar dos

esforços feitos até agora. Há que se realçar, é claro, que não se pode considerar o estudante latino em geral como parte de um grupo lingüisticamente homogêneo. ${ }^{2}$ Este trabalho, seguindo as linhas do livro Com licença! (Simōes 1991), ou seja, por razões práticas, evita separar o grupo latino como se explica no protocolo experimental.

Dois trabalhos que podem ser considerados pioneiros nesta área são aqueles de Ellison et al (1971) e Ulsh (1971). Embora o trabalho de Ellison et al tenha sido feito aparentemente para o estudante em geral, é um trabalho cuja pesquisa preliminar levou em consideração a presença do estudante com conhecimento da língua espanhola, como se pode ver no manual de orientação que acompanha o livro. $\mathrm{O}$ trabalho experimental dos Professores Lombello e Baleeiro (1983) da Universidade Estadual de Campinas-Unicamp, assim como o trabalho nas escolas secundárias do Texas como aqueles das professoras Irene Torres e Linda Calk, em El Paso, e os trabalhos das professoras Lillie Webb e Alma Hernandez, em Austin, também merecem atenção. Outros trabalhos com objetivos similares foram seguramente realizados e, se não os mencionamos, isto deve-se à falta de acesso a esses materiais. Mais recentemente, temos o livro Com licença! , um novo passo para estabelecer uma separaçāo desses grupos heterogêneos nos programas de português.

Portanto, nas universidades americanas, estudantes chegam aos programas de português como língua estrangeira via espanhol: ou falam espanhol fluentemente ou têm um bom conhecimentoda língua espanhola. A preparação de materiais de ensino para esses programas de português é mister que exige do educador estratégias de ensino que o levem a utilizar de modo eficaz as vantagens e desvantagens que o conhecimento 
do espanhol acarreta numa sala de aula, como bem frisou Jensen (1989a).

A solução aplicada cada vez mais a esse tipo de situação nos programas universitários é a de oferecer cursos de português intensivo. A esses estudantes se oferecem programas que permitam concluir cursos de um ano em um semestre. No caso de sistemas trimestrais organizam-se também programas similares. De uma maneira geral, esses programas intensivos são organizados em torno de uma aula, de uma hora quatro ou três vezes por semana. Definir exatamente oque vem a ser "intensivo"é bastante difícil, especialmente se levarmos em consideração os recentes enfoques didáticos dados ao ensino com base na noção de "competência comunicativa" (ing. "communicative competence") [Hymes 1971; Savignon 1983]. Caso o termo "intensivo" denote simplesmente passar em ritmo acelerado os materiais de um programa de ensino, neste caso nāo se está valendo do conhecimento já adquirido por esse tipo de estudante. Tampouco um ritmo de ensino simplesmente acelerado ajuda o estudante a transpor os obstáculos que irá encontrar durante o processo de aquisição da língua portuguesa, no caso deste estudo. Conseqüentemente não basta apenas ensinar em ritmo acelerado, mas sim, preparar um programa de ensino que aproveite os aspectos positivos do estudante e ao mesmo tempo identifique e proponha soluções em áreas potencialmente problemáticas.

O propósito deste estudo é o de examinar um dos vários obstáculos de relevância encontrados pelos estudantes de português em geral, especialmente os estudantes que chegam aos programas de português via espanhol, que é o processo de aquisição das vogais semi-abertas $/ \varepsilon$, ऽ/. Para analisaresse processo de aquisição selecionamos o manuscrito Com licença! (Simões 1991) por razões práticas e porque trata-se de um material de ensino que oferece alternativas para essa questão das vogais semi-abertas do português, tendo em vista as tendências pedagógicas atuais. Esperamos que esta investigação seja útil não só na preparação de Com licença!, mas também para outros materiais de ensino.

Neste estudo concentramo-nos no caso especifico do timbre vocálico das vogais médias portuguesas, ou seja, um estudo dentro do componente fonético-fonológico, porém temos que levar em consideração que outros componentes linguiísticos são importantes na comparação das duas línguas. Vejamos, por exemplo, o componente lexical. A aquisição de vocabulário é tão importante quanto a aquisição de pronúncia. Green (1988: 124) estima haver grande semelhança lexical (89\%) entre o português e o espanhol. Porém, uma interpretação correta desses números requer que levemos em consideração o fato de que esta comparação aplica-se melhor ao castelhano, ou seja ao espanhol centro-nortenho da Espanha e ao português de Portugal. Quanto ao espanhol em geral e ao português brasileiro, faz-se necessário outra interpretação. Intuitivamente, e se levarmos em conta o vocabulário básico de cerca de 1500 palavras do livro Com licença!, chegaremos à conclusão de que esta similaridade está em torno de $55-60 \%$. No entanto, somente um estudo quantitativo mais cuidadoso poderia confirmar essa diferença quando nos referimos ao português brasileiro. Essa menor similaridade léxica do português brasileirose explica pela presença de um vocabulário de alta frequiência no Brasil, proveniente de empréstimos de línguas africanas e de línguas indígenas do Brasil. Oficialmente esse vocabulário também está presente no português peninsular, mas o seu uso de facto é bem mais raro. O português peninsular, como o castelhano, ainda contém um léxico altamente influenciado pelas línguas árabes. Vemos assim que outros componentes lingüísticos além da pronúncia, requerem grande atenção no ensino do português (brasileiro)como língua estrangeira para estudantes fluentes em espanhol.

\section{Protocolo experimental}

Foram feitos testes preliminares de percepção com estudantes de português na Universidade do Texas, Austin e na Universidade do Kansas, Lawrence, com o objetivo de estabelecer a necessidade de continuação do trabalho. Em seguida, comprovada a confusão perceptual que essas vogais semi-abertas podem causar, tanto em análise subjetiva como em análise estatística, passamos a estudar dois grupos de estudantes em nível de produção na Universidade do Texas, em Austin.

No experimento a nível de produção, todos os informantes são estudantes de diferentes departamentos e diferente níveis universitários, matriculados no programa de português para o primeiro ano universitário na Universidade do Texas, em Austin. Participaram no grupo experimental estudantes da cadeira "First-Year Portuguese for Spanish Speakers." No grupo de controle estão os estudantes da cadeira regular de português. Foram escolhidos aleatoriamentequa- 
tro estudantes em cada um dos dois grupos. Não se estudaram fatores como idade, sexo ou proficiência em espanhol, porém os dois grupos de quatro estudantes contavam com estudantes dos sexos masculino e feminino. Os dois grupos reúnem-se 4 vezes por semana, em aulas de 50 minutos de duração. Os oito estudantes nos dois grupos estavam matriculados durante o primeiro semestre do ano escolar 1990-91 (Outono), num período de quinze semanas.

No começo do semestre o grupo de controle e o grupo experimental na Universidade do Texas, Austin e os grupos de estudantes em geral na Universidade do Kansas em Lawrence, participaram de testes de percepção com o objetivo de determinar como esses estudantes poderiam distinguir entre os timbres das vogais semi-abertas $/ \varepsilon, \mathrm{J} / \mathrm{e}$ das vogais semi-fechadas $/ \mathrm{e}, \mathrm{o} / \mathrm{Os}$ informantes receberam uma folha na qual havia instruções escritas indicando que eles ouviriam grupos de quatro palavras, sendo que três delas eram similares e uma diferente. Pediu-se aos estudantes que assinalassem qual das letras A, B, $\mathrm{Ce} D$ continha a palavra que soava diferente. As instruções foram explicadas oralmente com um exemplo antes de começar o teste. $\mathrm{O}$ teste era constituido de 18 grupos de palavras em pares mínimos, quatro para cada uma das vogais semiabertas e outras dez que foram incluidas por questōes de estratégia e conseqüentemente não foram usadas na análise (apêndice 1 contém o modelo dessa folha de instruções). $O$ grupo de palavras usadas como modelo para repetição, foi gravado por um brasileiro, EV, 40 anos, originário do Estado da Bahia. As gravações foram feitas em condições de controle, no laboratório de fonética da Universidade do Texas, em Austin. No caso do grupo de estudantes da Universidade do Kansas, foram feitas análises subjetivas preliminares dos resultados, segundo os casos mais evidentes em um primeiro estudo lingüístico do fenônemo. Em seguida, passamos aos grupos de estudantes da Universidade do Texas, para uma análise das diferenças significativas entre a percepção correta dos dois timbres. Esta segunda análise foi tratada estatisticamente por um teste$\mathrm{T}$ (alfa $\geq .01$ ).

Os grupos de controle e o grupo experimental, na Universidade do Texas, tiveram um teste preliminar de produção no laboratório de fonética, alguns dias depois do teste de percepção. Cada informante recebeu uma folha com 21 orações em português. As oraçōes que serviram de modelo foram gravadas pelo mesmo informante EV no teste de percepção. Estas oraçöes contêm muitos exemplos das vogais semi-abertas e semi-fechadas em estudo nesta investigação (v. apêndice 2). Por razões metodológicas, as primeiras e últimas dessas 21 orações não foram usadas e entre as orações restantes do corpus de análise foram escolhidos apenas vinte casos de ocorrência de vogais semi-abertas.

Pediu-se aos estudantes que escutassem as orações e em seguida tentassem imitar da melhor maneira possível as orações lidas por EV. Não se informou aos estudantes o objetivo do experimento. Os estudantes escutaram cada oração duas vezes, através de alto-falantes de ouvido, e deixaram gravadas suas repetiçōes em fita magnética. As gravações feitas por EV são de duas leituras da mesma oração escrita. Cada estudante ouviu as mesmas duas orações, ou seja, todos os fatores lingüísticos foram mantidos para cada estudante. Poder-se-ia argumentar que os estudantes foram meramente envolvidos em um exercício de leitura. Porém, devido à dificuldade e naturalidade das orações, não há outra maneira de conseguir com que os informantes produzam estas orações sem uma informação escrita.

Depois de terminadas as gravaçōes dos estudantes nos dois grupos, experimental e de controle, mediram-se as frequiências dos primeiros e segundos formantes de vinte ocorrências de vogais semi-abertas. Em termos relativos, a frequiência do primeiro formante correlaciona-se com altura vocálica e a frequiencia do segundo formante com movimentos de avanço e retração da língua. $\mathrm{O}$ propósito dessas medidas foi de identificar se ambos os grupos estudados poderiam ter èxito nesse aspecto da língua portuguesa, ou se apenas um dos dois grupos teria êxito. Nossa hipótese inicial foi a de que ambos os grupos, no começo do semestre, cometeriam erros de timbre vocálico. Depois do primeiro teste, os dois grupos só participaram em testes para este estudo no final do semestre. Durante o semestre, o grupo de controle recebeu instruções regulares nas salas de aula sem dar ênfase às diferenças de pronúncia. Por outro lado, o grupo experimental participou de práticas freqüentes com exercícios de pronúncia seguindo as instruções ainda em fase de preparação do livro de ensino Com licença!, usado nas aulas deste grupo. No final do semestre cada um dos grupos participou dos mesmos testes utilizados no começo do semestre. As mesmas condições foram mantidas.

Quanto à análise e segmentação dos sons aqui estudados, gostaríamos de fazer várias observações. Devido à grande complexidade que existe 
numa sequiência de sons da fala, há sempre muita incerteza no que toca às técnicas de segmentação desses sons. Daniel Hirst (contato pessoal) observa que há algum tempo, George Allen enviou cópias do mesmo espectrograma à vários foneticistas, para que cada foneticista fizesse a segmentação dos sons contidos no espectrograma. $O$ resultado desse estudo informal foi que não houve nenhuma coincidência na maneira como cada foneticista efetuou as segmentações e conseqüientemente cada som segmentado manualmente tinha durações diferentes. Em outras palavras, não devemos surpreender-nos com essa falta de coincidência em técnicas de segmentação manual de sons da fala. $\mathrm{O}$ importante é que o/a investigador/a desenvolva suas próprias técnicas de segmentação e que seja rigoroso/a na aplicação dessas técnicas. As técnicas aqui utilizadas foram rigorosamente seguidas. Essas técnicas de segmentação estão detalhadas em Simões (1987: 47ff), estabelecidas principalmente a partir dos trabalhos de Lehiste e Peterson (1961), Klatt (1976), Lieberman (1977) e Cole et al. (1980).

\section{Resultados}

Vemos no Quadro 1 os dados do teste de percepção e no Quadro 2 os resultados do teste T.

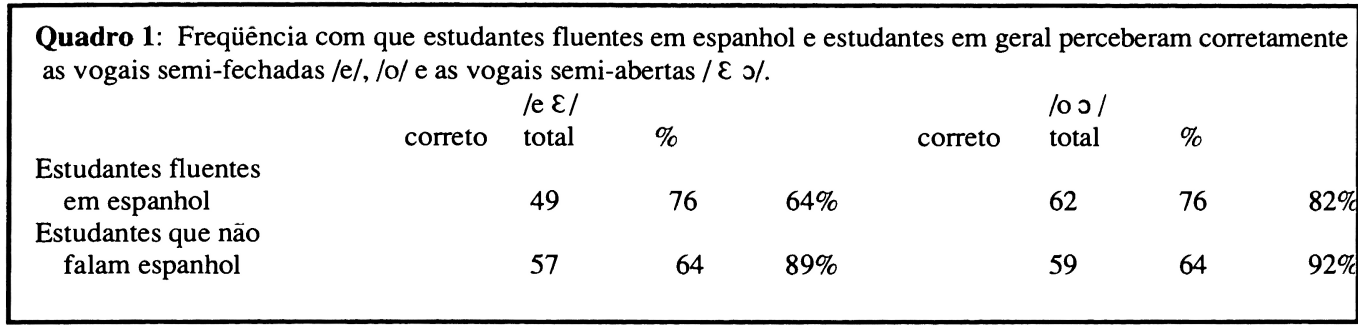

Quadro 2: percepção das vogais semi-abertas e semi-fechadas no grupo de controle e no grupo experimental, Teste T.

$/ \mathrm{e} / \mathrm{vs} / \varepsilon /$

$\mathrm{t}=-4.139, \mathrm{df}=33, \mathrm{p} \geq .01$ /o/ vs $/ 0 /$

$\mathrm{t}=-2.750, \mathrm{df} 33, \mathrm{p} \geq .01$
Estes testes preliminares de percepção foram realizados com o intuito de verificar se os estudantes cuja língua materna é o espanhol teriam vantagens ou desvantagens na percepção dos timbres vocálicos aberto e fechado. Se fosse o caso de uma vantagem desse grupo de estudantes, ou simplesmente resultados estatísticos sem consequiência, isso diminuiria a necessidade de elaboração de materiais de ensino que levassem em conta o timbre vocálico, no caso desse tipo de estudante. Os testes T, no entanto, confirmam que estas diferenças são significativas.

Uma análise dos dados apresentados no Quadro 1 sugere que estudantes cuja língua materna é o espanhol está em posição de desvantagem em relação a outros estudantes. No nosso estudo, $o$ grupo de estudantes em geral é composto predo- minantemente de estudantes cuja língua materna é o inglês, ou seja, estudantes que usam os fonemas $/ \varepsilon, \mathrm{J} / \mathrm{em}$ sua língua materna. Assim, esses resultados confirmam a utilidade que a preparação de materiais de ensino de timbre vocálico pode ter em português. Como mostra $\mathrm{o}$ Quadro 2, o grupo de controle, que não fala espanhol, identificou com mais precisão o timbre das vogais semi-fechadas no começo do semestre.

No Quadro 3 apresentamos a freqüència média do primeiro e segundo formantes nas vogais $/ \varepsilon /$ e $/ \mathrm{o} /$ O Quadro 4 mostra a frequiencia média do primeiro e segundo formante dessas mesmas vogais semi-abertas, no segundo teste de produção, administrado no final do semestre. 
Quadro 3: A freqüència média e o desvio padrão do primeiro e segundo formantes das vogais semi-abertas $/ \mathcal{E} / \mathrm{e}$

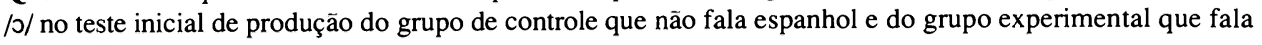
espanhol.

Quadro 3A

Grupo experimental

Freqüència média

Desvio padrão

\section{$\mathrm{F} 1$}

478.0

51.7
TESTE INICIAL / $/$ /

Grupo de controle

F2 F1

$1826.0 \quad 500.0$

$\begin{array}{ll}175.8 & 59.4\end{array}$
F2

1624.0

120.5

\begin{tabular}{lcllr}
\hline Quadro 3B & \multicolumn{4}{c}{ TESTE INICIAL / J/ } \\
& Grupo experimental & Grupo de controle & \\
& F1 & F2 & F1 & F2 \\
Freqüência média & 493.0 & 1005.0 & 498.0 & 972.0 \\
Desvio padrão & 55.5 & 134 & 45.6 & 90.5 \\
& & & & \\
& & TESTE FINAL /¿/ & \\
Freqüência média & 496.0 & 1014.0 & 489.0 & 1002 \\
Desvio padrão & 57.3 & 115.6 & 61.6 &
\end{tabular}

Devidoàs médias quase idênticas observadas no Quadro 3, ou seja os resultados não apresentam valores estatisticamente significativos, recorremos ao Teste T de correlação(ing. "matched
T-test") como vemos no Quadro 4. Uma vez mais, não se alcançou um valor estatisticamente significativo. Mais adiante, na interpretação dos resultados, tentaremos explicar mais detidamente esses resultados.

Quadro 4: O Teste-T de correlaçāo (ing. "matched T-test") comparando a diferença entre o teste inicial e o teste final.

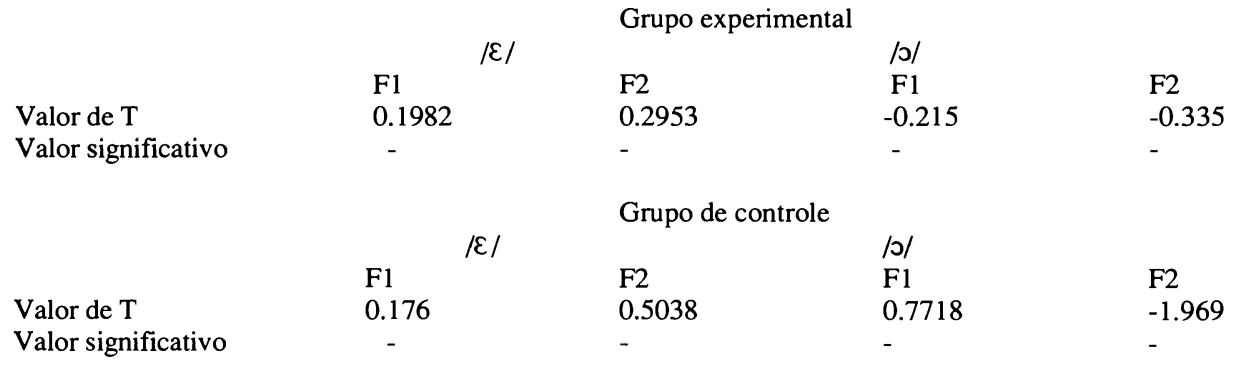

\section{Análise}

Antes de passar a uma análise mais detalhada dos resultados precedentes, faz-se necessário uma apresentação dos sistemas vocálicos do espanhol e do português. Limitamo-nos nesta apresentação ao escopo desta pesquisa porque já existem estudos completos nessas áreas, como é o caso dos estudos de cada sistema individualmente (Ludtke 1953; Alarcos Llorach 1974; Câmara 1949, 1975) ou em comparação (Williams
1975; Godínez 1978; Quilis 1979). Em uma análise fonético-fonológica em geral, assim como na presente análise, poderíamos partir da proposição de que tanto existem falsos cognatos fonéticos quanto falsos cognatos semânticos. Tais falsos cognatos fonéticos levam o estudante à uma pronúncia inapropriada dos sons do português brasileiro. $\mathrm{O}$ estudante em geral deixa-se levar pela similaridade ortográfica das duas línguas nesses deslizes de pronúncia. Vejamos como se comparam os dois sistemas vocálicos: 


\begin{tabular}{|c|c|c|c|}
\hline \multicolumn{2}{|c|}{ Espanhol } & \multicolumn{2}{|c|}{ Portuguès } \\
\hline $\mathrm{i} / \mathrm{i} /$ & piso "piso" & $\mathrm{i} / \mathrm{i} /$ & piso \\
\hline e $/ e /$ & peso "peso" & e /e/ & peso \\
\hline - & - & é $/ \mathcal{E} /$ & peço \\
\hline $\mathrm{a} / \mathrm{a} /$ & paso "passo" & $\mathrm{a} / \mathrm{a} /$ & passo \\
\hline $0 / 0 /$ & pozo "poço" & $\mathrm{o} / \mathrm{o} /$ & poço \\
\hline - & - & $0 / 0 /$ & posso \\
\hline $\mathrm{u} / \mathrm{u} /$ & puso "pôs" & $\mathrm{u} / \mathrm{u} /$ & puxo \\
\hline
\end{tabular}

Uma das características mais importantes do sistema vocálico do espanhol é a estabilidade relativa das vogais que resiste em espanhol desde épocas medievais. Essa estabilidade se mantém mesmo quando há mudanças de tonicidade, o que não vem a ser o caso em português especialmente em posição postônica. As vogais semiabertas "é, ó" não existem como fonemas no espanhol, embora possam ser observadas foneticamente. Em português as vogais semi-abertas "é, ó" são fonemas que aparecem em posição tônica e também em posição pretônica devido ao fenômeno fonológico de harmonia vocálica. Alguns exemplos dessa harmonia vocálica vêm mencionados no trabalho de Abaurre-Gnerre (1981) que cita as palavras "perereca," "pororoca," "abóbora" comumente pronuncia-

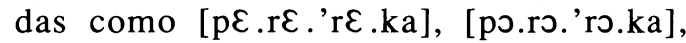
[a.'bo.bo.ra]. Emposiçãoátona, o sistema vocálico do português limita-se a cinco vogais /i, e, a, o, u/ como em "citado," "cevada," "lacuna," "coroa" e "urgente." Em posição postônica esse sistema reduz-se a três vogais: /i, a, u/ como nas palavras "come," "coma," "como." Vale observar que embora palavras como "come" e "como" sejam escritas com as letras "e" e "o," essas letras são, na realidade, pronunciadas como "i" e "u." O espanhol, por outro lado, apresenta essa estabilidade que o caracteriza e que mantém o mesmo sistema de cinco vogais, seja em posição pretônica, tônica ou postônica. Uma ilustração divertida dessa estabilidade pode ser observada no filme "The Milagro Beanfield War" onde a atriz brasileira Sônia Braga abre o filme com um envolvente "Listos?," deixando escapulir uma redução e conseqüentemente um levantamento vocálico da postônica "o," realizando assim uma transferência negativa comum entre nós, brasileiros, ou seja ['lis.tus] ao invés de ['lis.tos].

Observe-se que muitas palavras em português diferem semanticamente apenas no timbre das vogais semi-abertas e semi-fechadas:

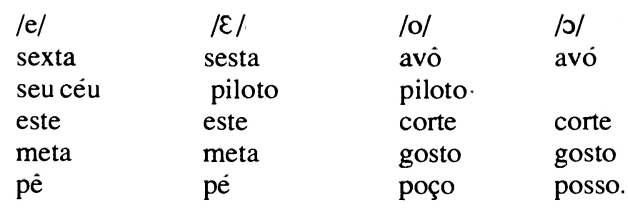

Estes exemplos servem para ilustrar como estudantes de português como língua estrangeira que não dominam este aspecto do componente fonológico do português terão dificuldades em fazer-se compreender em português. Observe-se que as letras " $e$ " e "o" em espanhol geralmente correspondem ao timbre fechado como nas palavras "mesa, mozo." Há exceções, é claro, em certos ambientes fonéticos, mas como regra, o timbre fechado predomina. Por essa razão, o estudante cuja língua materna é o espanhol tende a transferir negativamente essas características do espanhol. Na língua inglesa, por outro lado, quando a letra "e" recebe o acento principal em uma palavra, esta letra corresponde, via de regra, a uma vogal semi-aberta, como nas palavras "let, mess." Assim, no caso do estudante, cuja língua materna é o inglês, a tendência é de fazer sempre uso de um timbre aberto ao pronunciar uma letra "e" em posição acentuada. As alternâncias entre as articulações semi-abertas "é, ó" e as semifechadas "e, o" do português são problemáticas para estudantes fluentes em espanhol. Em nossa experiência, é curioso notar, temos observado que mesmo estudantes cuja língua materna é o inglês sentem dificuldades com essas vogais, uma vez que o espanhol esteja bem enraizado nesses estudantes.

As letras "e, o" do espanhol têm apenas uma pronúncia, ao passo que em português encontramos até mesmo quatro pronúncias, como nas palavras "demente" [de.'me.ti], "sete" ['sE.ti], "Botafogo" [bo.ta.'fo.gu]. Se consideramos em português os fatores: instabilidade vocálica, inconsistência da relação entre ortografia e pronúncia, número de vogais orais e nasais, que além desses fatores ainda existe muita semelhança, em nível abstrato (ing. "underlying level"), entre as duas línguas, podemos ver porque uma pessoa cuja língua materna é o português tem mais facilidade para compreender espanhol do que uma pessoa cuja língua materna é o espanhol teria para comprender português.

Nas Figuras 1 e 2 (AB) apresentamos um exemplo do tipo de análise que vimos fazendo para observar o progresso de cada estudante. A imagem acústica na Figura 1 corresponde à gravação do informante brasileiro; na Figura 2 temos as imagens acústicas das gravaçōes no começo e final do semestre de um dos estudantes que participaram no experimento. Como indicam os segundos formantes nestes espectrogramas, a distância entre o modelo e a imitaçāo é ainda enorme neste estudante. Isto confirma os resultados dos tratamentos estatísti- 
660 HISPANIA 74 SEPTEMBER 1991

cos. Em outras palavras, a questão do aprendizado das vogais semi-abertas persiste nos dois grupos. Assim sendo, nos dois grupos há estudantes que fizeram progresso, mas sem nenhuma indicação de que um dos grupos estivesse melhor que o outro, em termos geral. Ambos os grupos de controle e experimental apresentaram um progresso similar.

Figura 1: Frase modelo, gravada por EV: "A letra 'esse' parece uma cobra".

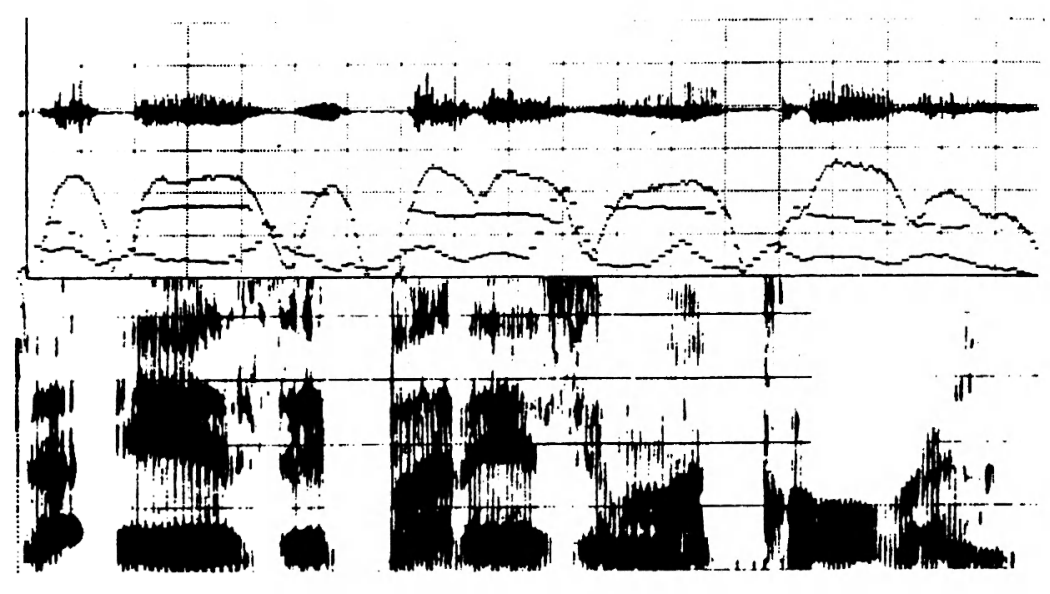

[ $\varepsilon$ s i p a r $\varepsilon$ s iũ ma $k$ o br a ]

Figura 2: Duas gravaçōes da frase "A letra 'esse' parece uma cobra" feitas por um dos estudantes, PD.

Figura 2A: Gravação realizada no início do semestre.

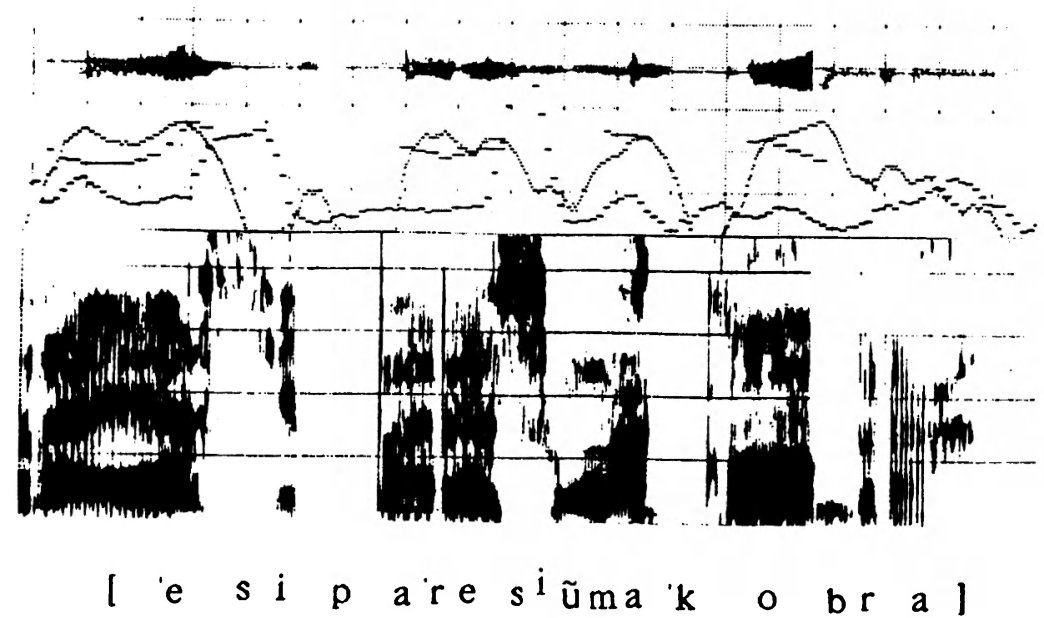


Figura 2B: Gravação de PD realizada no final do semestre.

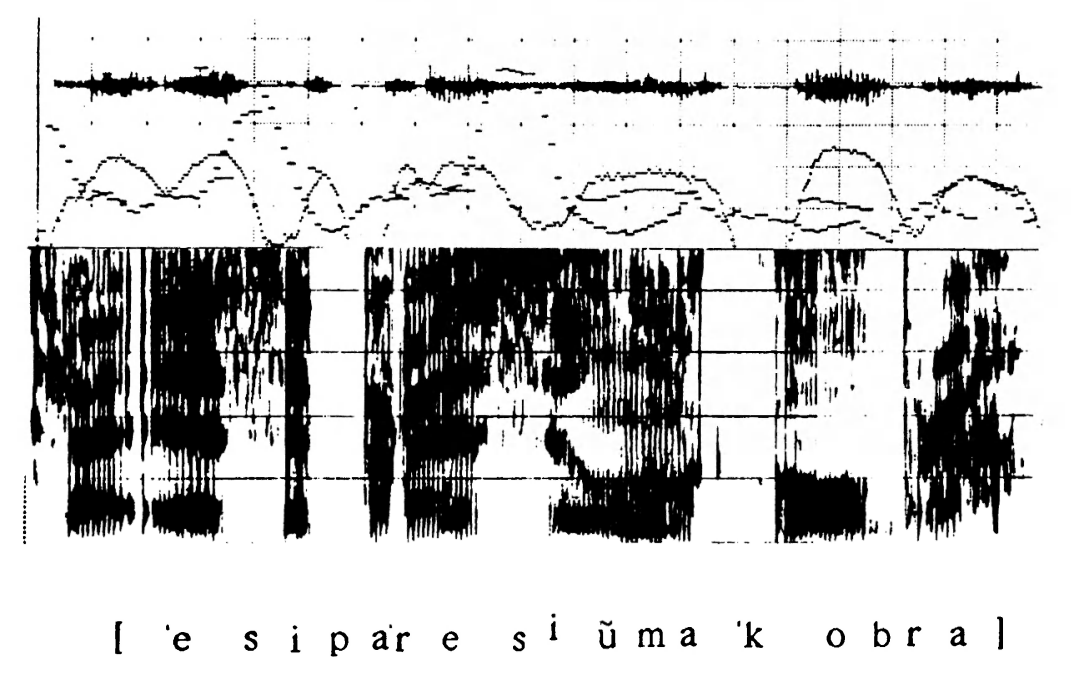

Apesar destes resultados não apresentarem valor estatístico significativo, estamos lidando com resultados altamente sugestivos. Poderemos entender as possibilidades de alcance que têm os estudos desta natureza se compararmos, por exemplo, os resultados deste estudo com o estudo de Nobre e Ingemann (1987). A freqüência média dos dois primeiros formantes (F1 and $\mathrm{F} 2)$ no português (brasileiro), segundo o estudo de Nobre e Ingemann, é a que citamos abaixo:

$\begin{array}{llllll} & \mathrm{F} 1 & \mathrm{~F} 2 & & \mathrm{~F} 1 & \mathrm{~F} 2 \\ / \varepsilon / & 516 & 1779 & \text { /o/ } & 538 & 1066 \\ / \mathrm{e} / & 424 & 1916 & \text { /o/ } & 424 & 1030\end{array}$

Estes números indicam que o timbre fechado tem uma influência muito grande na realização adequada do timbre aberto. Por razōes práticas, não foi possivel incluir nesta investigação, uma análise acústica das vogais semi-fechadas correspondentes, porém estamos conscientes de que esse tipo é de comparação será necessário em futuros estudos nessa área. O contraste entre os dois pares de vogais médias é realizado dentro de um espaço articulatório muito restringido, como indicam os formantes acima, no estudo de Nobre e Ingemann (op, cit.). Em outras palavras, o grupo experimental está em desvantagem em relação ao grupo de controle. Além dessa desvantagem vir confirmada nos números acima, já havíamos mencionado no início deste trabalho, que os testes de percepção também indicaram a necessidade de corrigir esta desvantagem do grupo experimental. Isso nos permite sugerir que talvez a elaboração de materiais didáticos dirigidos à correção deste problema seja o caminho certo apesar dos resultados presentes. Possivelmente, um semestre talvez não seja suficiente para que o método funcione. Dentro desta mesma linha de raciocínio podemos concluir que este estudo poderia ser expandido para incluir medidas e análise das vogais semi-fechadas correspondentes, oque abriria campo para interpretações que pudessem comprovar a necessidade desses materiais.

Lembramos que a preparação de materiais de ensino para minimizar uma falta de precisão do estudante em certas questão de pronúncia não deve, de nenhuma forma, levar a concluir que estamos propondo a criação de materiais de ensino que dêem ênfase à precisão na pronúncia. Deve-se sempre ter em mente que o presente trabalho trata de um caso de ensino de língua estrangeira que não é comum na área de ensino. Esta análise concentra-se no caso de estudantes que usam um conhecimento bastante enraizado do espanhol para chegar ao português. A língua que internalizaram tem a vantagem de estar muito próxima da língua que vão aprender, mas essa mesma proximidade faz com que o dommín apropriado do português seja um processo muito mais difícil do que o inglês, por exemplo. A proximidade das duas línguas deixa a falsa im- 
pressão de que se pode aprender a falar português com um esforço mínimo. Essa falsa expectativa leva os estudantes a uma surpresa muitas vezes desagradável e daí a um abandono da empreitada.

A aquisição das vogais abertas é apenas um dos muitos pontos de dificuldades desse tipo de estudante. Seria prematuro num estudo piloto como o que fizemos, esperar resultados definitivos. Buscou-se com o presente trabalho uma contribuição ao ensino do português do Brasil, que a nosso entender pode estender-se a outras áreas de estudos linguiísticos. A necessidade de tal estudo assim como da preparação de materiais que permitam ao estudante preparar-se era algo que todo professor que tenha lidado com essa questão na sala de aula pode reconhecer por experiência e intuição. $\mathrm{O}$ que nos faltava era comprovar essa necessidade empiricamente e quanto a isso achamos que nosso trabalho já cumpriu o seu objetivo, como vimos nos estudos preliminares de percepção aqui realizados. Encontramo-nos agora no estágio do trabalho em que lidamos com soluções para um problema já comprovado. Acreditamos que estamos bem mais próximos de uma solução do que estávamos antes do início desta pesquisa. A proposta de solução do manuscrito Com licença! nos parece ainda válida. Para os propósitos deste estudo, o livro foi reinterpretado, em parte, na sua orientação. Trata-se de um livro que propōe que pelo menos $80 \%$ das atividades na sala de aula sejam dedicadas ao uso da língua, um objetivo que, na prática, muitas vezes não chega a ser alcançado.

Mantemos nossa posição de que a questão das vogais semi-abertas é um dos fatores que os materiais didáticos para o ensino do português como língua estrangeira têm que levar em consideração. Sem contar com os componentes sintático, semântico, morfológico e discurso, há no componente fonético-fonológico do português, com o qual lidamos nesta investigação, um sem-número de princípios e características que o distinguem do espanhol. Neste artigo tratamos apenas de uma dessas características e princípios.

Portanto, as direções aqui tomadas são muito significativas, mas outros fatores na comparação das duas línguas têm que ser levados em conta. Entre esses, podemos prever, limitandonos ao componente fonético-fonológico, estudos e aplicações de materiais que tratem da instabilidade vocálica do português, e por conseguinte, da estabilidade vocálica e instabilidade consonântica do espanhol. Exemplos dessa ins- tabilidade consonântica no espanhol são muitos, especialmente no espanhol andaluz, e no espanhol das regiões planas ou baixas da América Latina onde as consoantes perdem suas características como vemos nos casos de debilitamento de consoante oclusiva em posição intervocálica (/ku.ña.do/ $\rightarrow$ [ku.' ña.ðo]), ${ }^{3}$ aspiraçāo de consoante fricativa alveolar surda em posição final de sílaba (/'es.tes/ $\rightarrow$ ['eh.teh]), lateralização de consoante líquida vibrante simples em final de sílaba (/per.der/ $\rightarrow$ [pel.'del]), velarização de consoante nasal alveolar em posiçāo final de palavra (/'pan/ $\rightarrow$ ['pan]. Vemos não somente um debilitamento ou instabilidade consonântica como também uma redução que pode chegar a um desaparecimento completo dessas consoantes nesses mesmos ambientes fonológicos: /ku.ña.do/ $\rightarrow$ [ku.'ña.o], /'es.tes/ $\rightarrow$ ['e.te]), /per.der/ $\rightarrow$ [pel.'de], /'pan/ $\rightarrow$ ['pã].

A título de conclusão, gostaríamos de examinar algumas idéias de aplicação didática sobre o timbre das vogais semi-abertas e semi-fechadas. Existem muitas alternâncias entre as vogais semiabertas e semi-fechadas que são idiosincráticas. Existem algumas tendências do português que ajudam na identificação do timbre vocálico e conseqüentemente, esperamos, na produção adequada desses sons do português. No correr do semestre os estudantes do grupo experimental receberam lições dirigidas ao ensino dessas tendências. Como vemos na proposta do livro Com licença!, essas orientações são dirigidas ao professor, para que faça uso dessa informação tendo em mente o seguinte. Como muitos educadores, acreditamos que o aprendizado de uma língua, seja a língua materna ou uma língua estrangeira, se faz por meio de dois processos: um processo natural e um processo consciente. Atualmente vemos uma grande tendência no uso exclusivo de um ensino "natural" (Krashen and Terrell 1983) nas salas de aula de língua estrangeira. Porém, o processo consciente também tem um papel relevante no aprendizado de uma língua materna ou estrangeira. As instruções abaixo são instruções daquilo que consideramos parte do processo consciente do aprendizado de línguas e que no livro Com licença! vem sugerido com o objetivo de ser usado sem nunca ultrapassar mais do que $20 \%$ de qualquer preparação de uma aula. São instruções dirigidas mais ao professor do que ao aluno. $\mathrm{O}$ professor pode, com essa informação levar ao estudante um conhecimento consciente da língua, através de qualquer atividade pedagógica. Alguns exemplos desse conhecimento consciente são os seguintes: 
A. Em português as vogais semi-abertas só aparecem em posição tônica, como já foi indicado acima, na comparação dos sistemas vocálicos do espanhol e do português. Com este tipo de conhecimento, os estudantes podem, de uma maneira geral, eliminar o timbre semi-aberto em palavras como "c[e]vada," "inv[e]joso," "m[o]rada," e "d[o]sagem;"

B. Há em português um sem-número de pares mínimos que podem ser agrupados segundo a classe gramatical dos membros desses pares. Assim, sabemos que em pares como "piloto" (subst.), "piloto"(v.) e "enterro" (subst.), "enterro" (v.), a tendência é a de que o substantivo leve o timbre semi-fechado enquanto que o verbo tem um timbre semi-aberto;

C. Também é comum as vogais semi-abertas $[\mathcal{E}][0]$ em português terem nas palavras correspondentes em espanhol os ditongos crescentes "ie" e "uo" respectivamente: (port.) $f[\varepsilon]$ sta e (esp.) "fiesta," (port.) "d[o]rme" e (esp.) "duerme";

Há outros grupos de palavras onde pode-se tentar descrições em benefício do aluno, como os grupos de adjetivos terminados em "-oso" ("famoso, gostoso") onde somente a forma masculina singular dessas terminaçōes apresenta uma vogal semi-fechada. Porém em um programa de primeiro ano o uso exagerado dessas descrições podem tomar muito tempo útil. Os casos apresentados acima em A. B. e C. parecem ser suficientes para um programa de primeiro ano. Os estudantes são informados sobre essas características através de lições variadas e contextualizadas que contêm pares mínimos, frases, parágrafos ou textos com os quais trabalham na percepçāo e produçāo dessas vogais.

\section{Apêndice 1}

Vemos a seguir as instruções e lista de palavras usadas nos testes preliminares de percepção. O interesse está na vogais semi-abertas "é, ó" /, $\emptyset /$. Por essa razão, somente os grupos de palavras com asteriscos são utilizados no experimento. Naturalmente, a cópia que o estudante recebe não contém nem os asteriscos, nem os sinais de acentuação, nem tampouco a indicação da pronúncia. Os outros grupos de palavras compõem uma estratégia de apresentação em relação a cada informante, ou seja apenas figuram no experimento. Naturalmente, este protocolo pode ser melhorado, se eliminamos por completo algumas indicações ortográficas que ainda permaneceram, como em "sesta/sexta"e"cassete/cacete." No entanto, durante as análises do corpus levamos em conta todos esses elementos do experimento.

Instructions: You will hear a set of four words. Three of the words are the same. Indicate which of the four is different by marking $\mathrm{A}, \mathrm{B}, \mathrm{C}$, or D. Example:

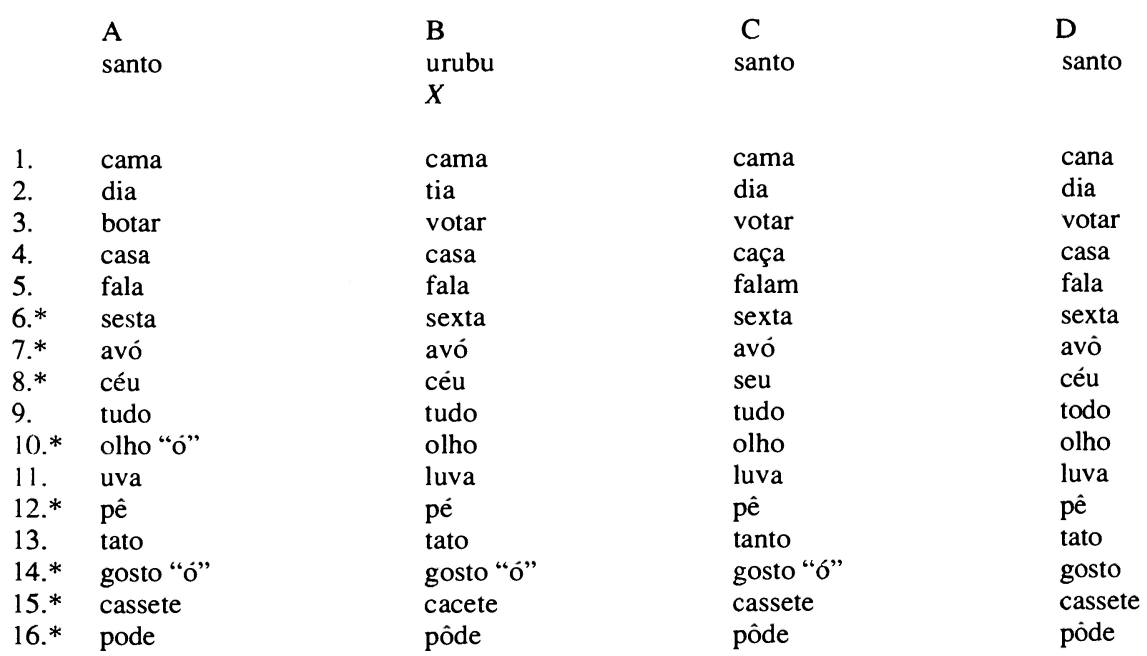




\section{Apêndice 2}

As orações abaixo foram primeiro escutadas e em seguida, repetida pelos informantes. Somente as vogais semi-abertas "é, ó" / $\mathcal{E}$, o/ nas oraçôes indicadas com um asterisco foram analisadas e medidas. Como se pode observar, só medimos os monotongos e os casos de abertura vocálica distintiva, ou seja em silaba tônica. $\mathrm{Na}$ oração 5, por exemplo, a harmonia vocálica faz com que o "e" pretônico em "Pelé" tenha, muitas vezes, uma abertura similar à vogal "e" tônica, porém incluir vogais semi-abertas por harmonia acarretaria em complicações desnecessárias a essa altura do nosso estudo devido a questões de interpretação dos resultados estatísticos.

Instructions: Listen to the following sentences and repeat them exactly as they are pronounced to you. You will hear each sentence twice and repeat it each time.

1 Quem espera nunca alcança.

2. As vezes, dois e dois são cinco.

3. Eu adoro a Teresa.

4. O netinho dele chega amanhā de manhā.

5. Seu Zózimo, feche a porta, por favor.

6.* O pessoal da bossa-nova tem bom gosto.

7.* Cuidado que esse sol "tá quente à beça.

8.* Essa caneta é sua?

9. Cadè a bola do Pelé?

10.* O concerto começa às nove horas.

11.* A letra "esse" parece uma cobra.

12. Mostra essa borboleta só pra ela, pra ele nāo.

13.* Minha nossa! Olha o seu rosto.

14. Filhinho, você não pode pintar o céu de amarelo.

15. O petróleo é nosso.

16.* Ei! Peça ao boy pra trazer o nosso almoço.

17. Aurélio, você é mesmo um cabeça de martelo, hein.

18.* Pedro, é melhor você não ficar por perto.

19. É inútil dormir que a dor não passa.

20. Espere sentado porque em pé você se cansa.

21. Pra mim, isso não está certo.

\section{NOTAS}

1 A este propósito recentemente um grupo de oito especialista vem preparando este tipo de exame para o português brasileiro com o apoio do Projeto Alcance, Universidade do Texas, Austin.

${ }^{2}$ Agradecemos ao resenhista anónimo de Hispania a observaçāo feita a respeito desse ponto.

${ }^{3}$ Preferimos não mencionar todos os detalhes fonéticos que entram em jogo nesses processos e simplemente fazer uso dos símbolos fonéticos que nos parecem suficientes nesta exposição.

\section{OBRAS CITADAS}

Abaurre-Gnerre, M.B. 1981. "Processos fonológicos segmentais como índice de padrōes prosódicos diversos nos estilos formal e casual do português do Brasil." Cadernos de estudos lingüísticos 2: 23-44.

Alarcos Llorach, E. 1974. Fonología española. Madrid:
Gredos.

Barbosa, J. Morais. 1965. Etudes de phonologie portugaise. Lisboa: Junta de Investigaçōes do Ultramar.

Barrutia, Richard and Tracy Terrell. 1982. Fonética y fonología españolas. New York: Wiley.

Bisol, Leda. 1989. "Vowel Harmony: A Variable Rule in Brazilian Portuguese." Language Variation and Change 1: 185-98.

Câmara, J. Mattoso. 1949. Para o estudo da fonemática portuguesa.

1975. História e estrutura da língua portuguesa. Rio de Janeiro: Padrāo.

Cole, R. A., A. I. Rudnick, V. W. Zue and D. R. Reddy. 1980. "Speech as Patterns on Paper." R.A. Cole (ed.), Perception and Production of Fluent Speech. New Jersey: Earlbaum.

Ellison et al. 1971. Modern Portuguese. New York: Knopf.

Fant, C.G.M. 1970. Acoustic Theory of Speech Production. The Hague: Mouton

Godínez, M. 1978. "A Survey of Spanish and Portuguese Phonetics." UCLA Working Papers in Phonetics.

Green, John N. 1988. "Spanish." Martin Harris and Nigel Vincent (eds.), The Romance Languages. New York: Oxford University Press. 79-130.

Hymes, D. 1971. "Competence and Performance in Linguistic Theory." R. Huxley and E. Ingram (eds.), Language Acquisition: Models and Methods. London: Academic Press.

Jensen, John B. 1989a. "Evaluating Portuguese Performance of Spanish-Speaking Students." D. A. Koike and A. R. M. Simões (eds.), Negotiating For Meaning: Papers on Foreign Language Teaching and Testing. Austin, TX: Department of Foreign Language Education Studies, University of Texas. 119-30. $1989 \mathrm{~b}$. "On the Mutual Intelligibility of Spanish and Portuguese." Hispania 72: 848-52.

Klatt, D. H. 1976. "Segmental Duration in English." Journal of the Acoustical Society of America 59: 1208-21.

Krashen, S. D. and T. Terrell. 1983. The Natural Approach: Language Acquisition in the Classroom. Hayward, CA: Alemany Press.

Lehiste, I. and G. E. Peterson. 1961. "Transitions, Glides, and Dipthongs." Journal of the Acoustical Society of America 33: 268-77.

Lieberman, Ph. 1977. Speech Physiology and Acoustic Phonetics: An Introduction. New York: MacMillan Pub.

Lombello, L. C. e Marisa de A. Baleeiro. 1983. Português para falantes de espanhol. Campinas: UNICAMP/ FUNCAMP/MEC: Instituto de estudos de linguagem.

Ludtke, H. 1953. "Fonemática portuguesa: 2. vocalismo." Boletim de filologia 14: 197-217.

Nobre, M. A. e F. Ingemann. 1987. “Oral Vowel Reduction in Brazilian Portuguese.” R. Channon and L. Shockey, (eds.), In Honor of Ilse Lehiste. Dordecht-Holand, Providence-USA.

Foris Publications. 195-206.

Parker, E. M. and R. L. Diehl. 1984. "Identifying Vowels in CVC syllables: Effects of Inserting Silent and Noise." Perception and Psychophysics 36.4: 369-80.

Parkinson, Stephen. 1988. "Portuguese." Martin Harris and Nigel Vincent (eds.), The Romance Languages. New York: Oxford University Press. 130-69.

Peterson, G. E. and I. Lehiste. 1960. "Duration of Syllable Nuclei in English." Journal of the Acoustical Society of America 32: 693-703.

Quilis, Antonio. 1981. Fonética acústica de la lengua española. Madrid: Gredos. 


\section{O PROCESSO DE AQUISIÇÃO DAS VOGAIS SEMI-ABERTAS 665}

1979. "Comparación de los sistemas fonológicos del español y portugués." Revista española de lingüística 9: 1-22.

Savignon, S. J. 1983. Communicative Competence: Theory and Classroom Practice. Reading, MA: AddisonWesley.

Simōes, A. R. M. 1987. "Temporal Organization of Brazilian Portuguese Vowels in Continuous Speech: An Acoustical Study."Unpub. diss. Univ. of Texas-Austin.
1991. Com licença! Brazilian Portuguese for Spanish Speakers. Austin, TX: University of Texas Press and Institute of Latin American Studies-ILAS.

Stravrou, C. 1974. Brazilian-Portuguese Pronunciation. New York: Knopf.

Ulsh, J.L. 1971. From Spanish to Portuguese. Washington, D.C.: Department of Education.

Williams, E. B. 1975. Do latimao português, trans. Antônio Houaiss. Rio de Janeiro: Tempo Brasileiro. 